\title{
Serum Triglyceride Lowering Effect of Cilnidipine in Patients With Essential Hypertension
}

\author{
Prakash Kumar $^{\mathrm{a}}$, Arijit Das ${ }^{\mathrm{b}, \mathrm{c}}$, Satish Chandra ${ }^{\mathrm{b}}$, Manju Gari ${ }^{\mathrm{b}}$, U. S. P. Keshri ${ }^{\mathrm{b}}$, \\ Kusum Kumari ${ }^{b}$
}

\begin{abstract}
Background: Many epidemiological studies have established the relationship between hypertension and dyslipidemia. Calcium channel blockers (CCBs) are one of the first-line drugs for newly diagnosed patients with essential hypertension. Cilnidipine as a newer CCB acting by blocking both L- and N-type calcium channels possesses additional beneficial effects apart from lowering blood pressure (BP). The aim of this study was to evaluate the effectiveness of cilnidipine in patients with essential hypertension with borderline dyslipidemia and its effects on lipid profile.
\end{abstract}

Methods: Out of 45 enrolled patients, who fulfilled the inclusion criteria, only 37 completed the study. Cilnidipine was started at $10 \mathrm{mg} /$ day, and then adjusted to $5-20 \mathrm{mg}$ /day to achieve the target blood pressure.

Results: After 12 weeks of study, patients showed significant reduction in systolic blood pressure, diastolic blood pressure, mean BP, heart rate and serum triglyceride level from baseline values $(\mathrm{P}<0.00)$.

Conclusion: In clinical setting where both hypertension and hypertriglyceridemia exist, cilnidipine can be a promising drug of choice.

Keywords: Hypertension; Heart rate; Dyslipidemia; Hypertriglyceridemia; L- and N-type calcium channel blocker; Cilnidipine

\section{Introduction}

Hypertension is ranked as the third most, important risk factor for attributable burden of disease in South Asia. Around the globe, about 1 billion patients are affected by hypertension and

Manuscript accepted for publication October 18, 2016

aDepartment of Cardiology, Rajendra Institute of Medical Sciences (RIMS), Ranchi, India

bepartment of Pharmacology, Rajendra Institute of Medical Sciences (RIMS), Ranchi, India

${ }^{\mathrm{c} C}$ Corresponding Author: Arijit Das, Department of Cardiology, Rajendra Institute of Medical Sciences (RIMS), Ranchi 834009, Jharkhand, India.

Email: prakash11may@gmail.com

doi: http://dx.doi.org/10.14740/cr497w the burden is rising owing to escalating obesity and population aging and by 2025 it is projected that about 1.5 billion of patients will be affected worldwide [1].

Cardiovascular risk factors, including hypertension, tend to co-segregate more commonly than would be expected by chance. Approximately $40 \%$ of persons with essential hypertension also have dyslipidemia. Genetic studies have established a clear association between hypertension and dyslipidemia [2]. The term dyslipidemic hypertension (DH) was first used in 1988, in the context of familial dyslipidemia along with hypertension [3], which was proposed as a genetic syndrome found in approximately $12 \%$ of the patients with essential hypertension and $48 \%$ of the hypertensive sib ships [4]. Non-familial forms of DH are more common than the familial ones. Dyslipidemia, a strong predictor of cardiovascular disease (CVD) [5], causes endothelial damage [6-9], and the loss of physiological vasomotor activity that results from endothelial damage may become manifested as increased blood pressure (BP). Therefore, factors like dyslipidemia that cause endothelial dysfunction may lead to hypertension.

According to recent "Joint National Committee 8 guidelines", calcium channel blockers (CCBs) are one of the firstline recommended drugs for the treatment of hypertension [10]. Out of various subtypes of $\mathrm{Ca}^{2+}$ channels (i.e. L, N, T, $\mathrm{P} / \mathrm{Q}$, and $\mathrm{R}$ ), clinically used common CCBs act on primarily $\mathrm{L}-$ type, T-type and N-type calcium channels. Structurally, CCBs are divided into the dihydropyridine type and the non-dihydropyridine type $[11,12]$.

By regulating the release of norepinephrine from sympathetic nerve ending, the N-type voltage-dependent calcium channel plays an important role in sympathetic neurotransmission [11]. Cilnidipine is a novel and unique 1,4-dihydropyridine derivatives calcium antagonist with potent inhibitory action against both L-type and N-type voltage-dependent calcium channels [12]. It has been reported that once daily administration of cilnidipine resulted in a safe and more effective lowering of BP in essential hypertension without reflex tachycardia than similar administration of other dihydropyridine calcium antagonists [13].

The renin-angiotensin-aldosterone system (RAAS) promotes atherogenesis. Angiotensin II, a major villain of the RAAS pathway, promotes atherogenesis through stimulation of the angiotensin type 1 receptor (AT1), which increases lipid uptake in cells, vasoconstriction, and free radical production, to foster both hypertension and atherosclerosis [14].

In animal models, N-type CCBs not only suppress the 
sympathetic overactivity but also have cardioprotective and renoprotective effects. RAAS can be suppressed through the sympatholytic actions of N-type CCBs [15].

BP-lowering drugs have a certain impact on the lipid levels. These changes in lipid levels are important in hypertensives, as up to $40 \%$ of the newly diagnosed hypertensives have at least one lipid abnormality [16]. Considering the effect on plasma lipid alpha-blockers, the RAAS blocker or the CCB may be the preferred initial therapy in patients with underlying dyslipidemia [10].

Among the various groups of antihypertensive drugs available in the market, selecting the appropriate drug as per individual clinical profile of patient is of utmost importance.

\section{Aim}

The aim of this study was to evaluate the effectiveness of cilnidipine in patients with essential hypertension with borderline dyslipidemia and its effects on lipid profile.

\section{Materials and Methods}

\section{Study design}

This was an interventional, randomized, open-label, parallel assignment, effectiveness study.

\section{Subjects}

We enrolled 45 patients with newly diagnosed essential hypertension along with borderline high lipid profile who presented to Outpatient Clinic of Cardiology, Rajendra Institute of Medical Sciences (RIMS), Ranchi, during January 2016. Patients were followed up for a period of 12 weeks. Patients were included in the study if they met the following criteria: $\geq$ 40 years of age of both sex, systolic blood pressure (SBP)/diastolic blood pressure (DBP) of $\geq 140 / 90 \mathrm{~mm} \mathrm{Hg}$ to $\leq 180 / 110$ $\mathrm{mm} \mathrm{Hg}$, borderline dyslipidemia not requiring drug treatment (total cholesterol $200-239 \mathrm{mg} / \mathrm{dL}$ and/or triglyceride 150 $199 \mathrm{mg} / \mathrm{dL}$ and/or LDL $130-159 \mathrm{mg} / \mathrm{dL}$ and/or HDL $40-60$ $\mathrm{mg} / \mathrm{dL}$ ). Patients with secondary hypertension of any causes, angina pectoris or acute coronary artery disease, recent history of congestive heart failure, valvular heart diseases, cardiac arrhythmias, renal dysfunction (serum creatinine level $>$ $2.0 \mathrm{mg} / \mathrm{dL}$ ) and diabetes mellitus were excluded. Pregnant patients and breast-feeding mothers were also excluded. Patients of any existing clinical condition which did not allow safe completion of the protocol and safe administration of study medication were also excluded. Target SBP and DBP were $<$ 140 and $90 \mathrm{~mm} \mathrm{Hg}$, respectively. Eligible study subjects were treated with cilnidipine started at $10 \mathrm{mg} / \mathrm{day}$, and then adjusted to $5-20 \mathrm{mg} /$ day if target BP was not achieved by 4 weeks. If cilnidipine failed to reduce the BP to the target level, an angiotensin-converting-enzyme (ACE) inhibitor and/or angiotensin II receptor blocker (ARB) were added and these patients were
Table 1. General Characteristics of Patients of Amlodipine and Cilnidipine Groups

\begin{tabular}{ll}
\hline $\mathrm{N}$ & 37 \\
Male & 22 \\
Female & 15 \\
Age (years) & $54.17 \pm 3.35$ \\
Body weight $(\mathrm{kg})$ & $69.54 \pm 7.65$ \\
Height $(\mathrm{cm})$ & $160.55 \pm 5.19$ \\
BMI & $27.31 \pm 3.7$ \\
\hline
\end{tabular}

excluded from the study. Duration of follow-up was 12 weeks for each patient. Patients were followed on second, fourth, eighth and 12th week and at each visit in office, SBP and DBP and heart rate were recorded. $\mathrm{BP}$ was recorded three consecutive times and the average was taken as final value, using mercury sphygmomanometer. The 12-h fasting blood samples were taken at baseline and at 12th week between 9 am and 11 am lipid profile was measured by an automatic biochemical analysis system.

\section{Ethics}

This study was conducted in accordance with the principles outlined in the Declaration of Helsinki after receiving approval from the institutional ethical committee of RIMS, Ranchi. All subjects provided written informed consent prior to participation.

\section{Statistical analysis}

The primary outcomes included changes in heart rate, SBP, DBP and lipid profile in hypertensive patients following 12 weeks treatment with cilnidipine. Continuous data were presented as mean and standard deviation (SD). We compared values at baseline and after treatment using the " $Z$ " test. All results were expressed as mean $\pm \mathrm{SD}$. P values $<0.05$ were considered significant. Statistical computations were performed with Microsoft Excel 2014 version.

\section{Results}

\section{Patient characteristics}

We analyzed the data of 22 men and 15 women with mean age of $54.17 \pm 3.35$ years and mean body mass index (BMI) of $27.31 \pm 3.7$. Out of initially enrolled 45 patients, eight were lost in follow-up or excluded from the study due to side effects or inadequate control of BP with study medication by eighth week or due to requirement of lipid-lowering drug during the first 4 weeks of the study.

Table 1 summarizes the baseline characteristics of the patients enrolled for this study. There were no significant differ- 
Table 2. Comparison Data (SBP, DBP, mean BP, Heart Rate and Lipid Profile) of Baseline and After 12 Weeks Treatment Along With Corresponding $P$ Values

\begin{tabular}{llll}
\hline & Baseline & 12th week & P \\
\hline SBP & $156.66 \pm 5.89$ & $132.58 \pm 5.97$ & $0.00^{*}$ \\
DBP & $94.76 \pm 3.77$ & $78.36 \pm 3.66$ & $0.00^{*}$ \\
Mean BP & $115.47 \pm 3.83$ & $97.53 \pm 2.6$ & $0.00^{*}$ \\
Heart fate & $75.77 \pm 4.21$ & $73.47 \pm 3.33$ & $0.00^{*}$ \\
Total cholesterol & $220.51 \pm 10.72$ & $218.78 \pm 9.04$ & 0.45 \\
Triglyceride & $172.46 \pm 13.42$ & $162.46 \pm 10.87$ & $0.00^{*}$ \\
LDL & $145.30 \pm 8.78$ & $143.97 \pm 8.05$ & 0.49 \\
HDL & $49.70 \pm 5.67$ & $49.27 \pm 6.55$ & 0.76 \\
\hline
\end{tabular}

*Significant.

ences in background factors before and after the study.

Table 2 shows SBP, DBP and mean BP decreased significantly after treatment with cilnidipine. Heart rate reduced significantly from baseline. In the lipid profile, while total cholesterol, LDL and HDL showed no significant change, serum triglyceride level reduced significantly after 12 weeks of treatment by cilnidipine from the baseline values.

\section{Discussion}

In the present study, there was a significant reduction in of- fice BP readings (Fig. 1). Heart rate after 12 weeks of treatment significantly decreased (Fig. 2). Probable explanation for significant reduction of heart rate is the inhibition of cardiac sympathetic overactivity by blocking L- and N-type calcium channels [17]. Similar reduction of heart rate in cilnidipine treated patients has also been reported in other studies [18]. High heart rate is a known independent risk factor for cardiovascular death. Increase mortality from CVD in Japanese population [11, 12] and in American [19] patients with hypertension has been observed to be associated with a higher heart rate. Reflex tachycardia is a common side effect associated with many dihydropyridine CCBs which act through L-type calcium channel only. Replacing these drugs with cilnidipine, a dual L- and N-type CCB may reduce the heart rate and can potentially reduce the mortality in hypertensive patients.

In this study, we showed that after 12 weeks of treatment, there is a significant reduction in the level of triglyceride (Fig. 3). Similar reduction of triglyceride was found in hypertensive rats fed with high fat diet and studies done in patients of type 2 diabetes with hypertension treated with cilnidipine [20-23]. By blocking the N-type calcium channel, cilnidipine, indirectly causes blockade of the $\alpha$-receptors and improves the lipid profile by producing peripheral vasodilation, which may facilitate glucose and lipid uptake by muscle cells. Furthermore, $\alpha$-receptor blockade may also increase the availability of lipoprotein lipase for triglyceride hydrolysis. Blockade of hepatic $\alpha$-1-adrenoceptors may modulate glycogenolysis and gluconeogenesis, decrease triglyceride output from the liver, reduce cholesterol synthesis, and accelerate binding of LDLs to their hepatic receptors [24]. Although the role of triglyc-

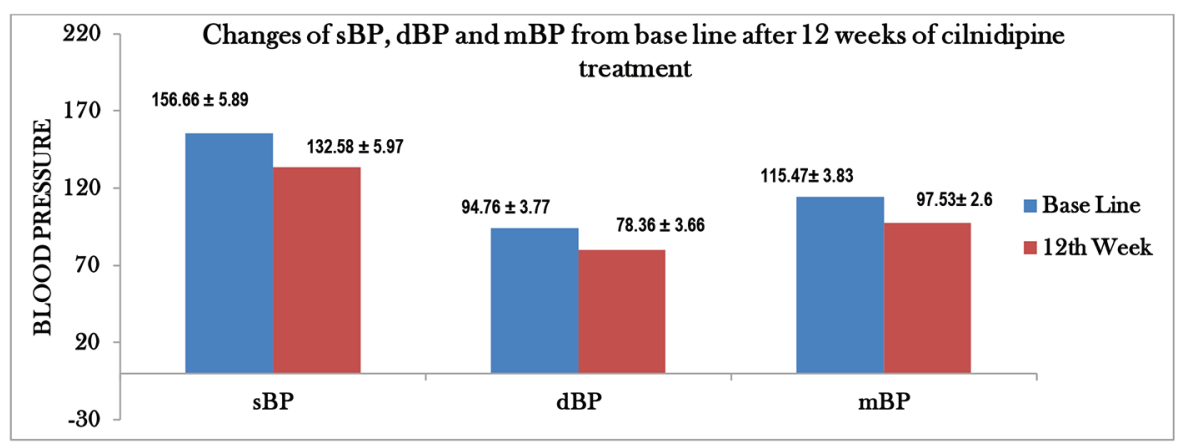

Figure 1. Graphical representation of changes of SBP, DBP and mean BP from baseline after 12 weeks of cilnidipine treatment.

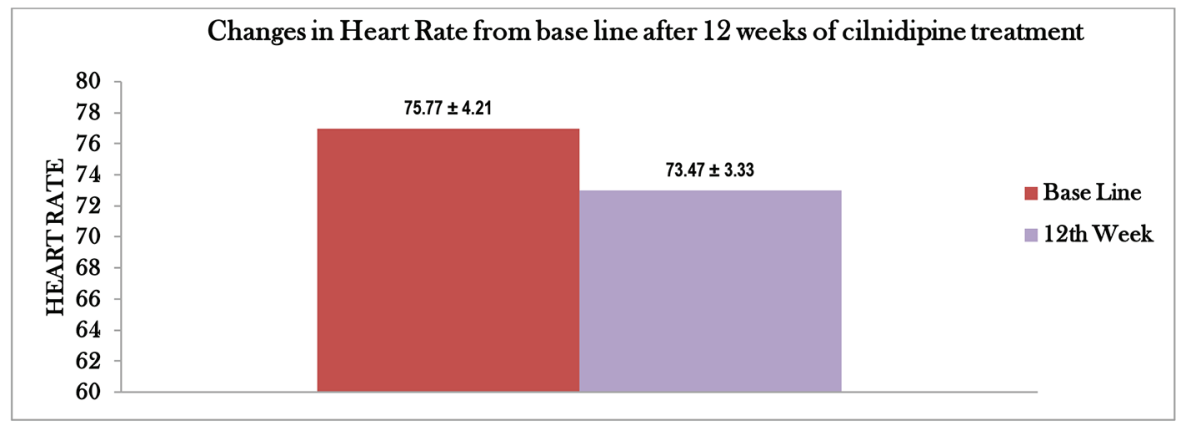

Figure 2. Graphical representation of changes in heart rate from baseline after 12 weeks of cilnidipine treatment. 


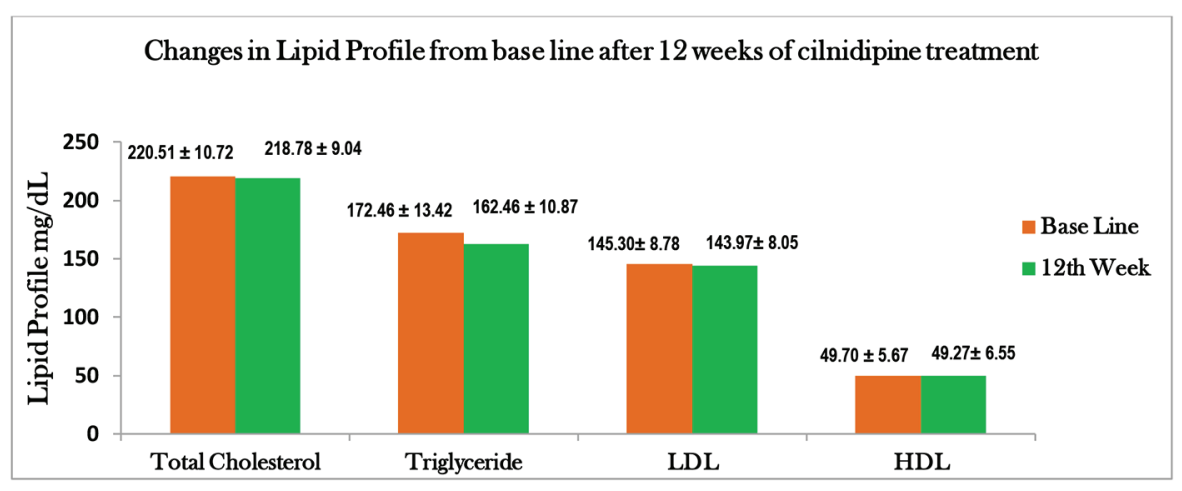

Figure 3. Graphical representation of variation in lipid profile, before and after 12 weeks of treatment.

erides as an independent risk factor for CVD has been under debate, there is increasing evidence from recent studies demonstrating moderately high triglycerides $(150-500 \mathrm{mg} / \mathrm{dL})$ are associated with increased cardiovascular risk [25]. In a recently published meta-analysis involving more than 200,000 patients from 29 studies (including the Reykjavik Study and the EPICNorfolk Study), moderately strong associations were observed between triglyceride concentrations and chronic heart disease (CHD) risk even with low baseline triglyceride concentrations. It has been suggested that the attenuation of the effect of triglycerides on the prediction of future CHD events when HDL cholesterol and other risk factors are included in models is due to the biological variability of triglycerides compared with that of HDL [26]. When this variability is taken into account, triglycerides have greater predictive power on future CHD events [27].

Cilnidipine by virtue of its triglyceride reducing property may provide better mortality protection in hypertensive patients.

\section{Limitations}

A small number of patients were enrolled in this study for a period of 12 weeks only. Therefore, a large number of patients and long-term follow-up may be needed to confirm the consistency our results.

\section{Conclusion}

Taken together, the results from this study allow us to conclude that cilnidipine (N- and L-type CCBs) exerts hypotensive activity, and on the other hand, unlike other dihydropyridine, it reduces heart rate and also improves triglyceride level. Considering these features, cilnidipine is a promising drug of choice for targeting patients with hypertension and hypertriglyceridemia, since both disorders often coexist in clinical setting.

\section{Grants}

The study was not supported by any grants or funding agen- cies.

\section{Conflicts of Interest}

The authors declare no conflicts of interest.

\section{References}

1. Lawes CM, Vander Hoorn S, Rodgers A. Global burden of blood-pressure-related disease, 2001. Lancet. 2008;371(9623):1513-1518.

2. Selby JV, Newman B, Quiroga J, Christian JC, Austin MA, Fabsitz RR. Concordance for dyslipidemic hypertension in male twins. JAMA. 1991;265(16):2079-2084.

3. Williams RR, Hunt SC, Hopkins PN, Stults BM, Wu LL, Hasstedt SJ, Barlow GK, et al. Familial dyslipidemic hypertension. Evidence from 58 Utah families for a syndrome present in approximately $12 \%$ of patients with essential hypertension. JAMA. 1988;259(24):3579-3586.

4. Williams RR, Hopkins PN, Hunt SC, Wu LL, Hasstedt SJ, Lalouel JM, Ash KO, et al. Population-based frequency of dyslipidemia syndromes in coronary-prone families in Utah. Arch Intern Med. 1990;150(3):582-588.

5. Anderson KM, Castelli WP, Levy D. Cholesterol and mortality. 30 years of follow-up from the Framingham study. JAMA. 1987;257(16):2176-2180.

6. Nickenig G. Central role of the AT(1)-receptor in atherosclerosis. J Hum Hypertens. 2002;16(Suppl 3):S26-33.

7. Nickenig G, Harrison DG. The AT(1)-type angiotensin receptor in oxidative stress and atherogenesis: Part II: AT(1) receptor regulation. Circulation. 2002;105(4):530536.

8. Nickenig G, Harrison DG. The AT(1)-type angiotensin receptor in oxidative stress and atherogenesis: part I: oxidative stress and atherogenesis. Circulation. 2002;105(3):393-396.

9. Niskanen LK, Laaksonen DE, Nyyssonen K, Alfthan G, Lakka HM, Lakka TA, Salonen JT. Uric acid level as a risk factor for cardiovascular and all-cause mortality in middle-aged men: a prospective cohort study. Arch Intern Med. 2004;164(14):1546-1551. 
10. James PA, Oparil S, Carter BL, Cushman WC, Dennison-Himmelfarb C, Handler J, Lackland DT, et al. 2014 evidence-based guideline for the management of high blood pressure in adults: report from the panel members appointed to the Eighth Joint National Committee (JNC 8). JAMA. 2014;311(5):507-520.

11. Fujii S, Kameyama K, Hosono M, Hayashi Y, Kitamura K. Effect of cilnidipine, a novel dihydropyridine $\mathrm{Ca}++$-channel antagonist, on $\mathrm{N}$-type $\mathrm{Ca}++$ channel in rat dorsal root ganglion neurons. J Pharmacol Exp Ther. 1997;280(3):1184-1191.

12. Hirning LD, Fox AP, McCleskey EW, Olivera BM, Thayer SA, Miller RJ, Tsien RW. Dominant role of N-type $\mathrm{Ca} 2+$ channels in evoked release of norepinephrine from sympathetic neurons. Science. 1988;239(4835):57-61.

13. Feig DI, Kang DH, Johnson RJ. Uric acid and cardiovascular risk. N Engl J Med. 2008;359(17):1811-1821.

14. Iseki K, Oshiro S, Tozawa M, Iseki C, Ikemiya Y, Takishita S. Significance of hyperuricemia on the early detection of renal failure in a cohort of screened subjects. Hypertens Res. 2001;24(6):691-697.

15. Uchida S, Takahashi M, Sugawara M, Saito T, Nakai K, Fujita M, Mochizuki K, et al. Effects of the N/L-type calcium channel blocker cilnidipine on nephropathy and uric acid metabolism in hypertensive patients with chronic kidney disease (J-CIRCLE study). J Clin Hypertens (Greenwich). 2014;16(10):746-753.

16. Ross R. Atherosclerosis - an inflammatory disease. N Engl J Med. 1999;340(2):115-126.

17. Bottger A, van Lith HA, Kren V, Krenova D, Bila V, Vorlicek J, Zidek V, et al. Quantitative trait loci influencing cholesterol and phospholipid phenotypes map to chromosomes that contain genes regulating blood pressure in the spontaneously hypertensive rat. J Clin Invest. 1996;98(3):856-862.

18. Kannel WB, Carter BL. Initial drug therapy for hypertensive patients with hyperlipidemia. Am Heart J.
1989;118(5 Pt 1):1012-1021.

19. Hoshide S, Kario K, Ishikawa J, Eguchi K, Shimada $\mathrm{K}$. Comparison of the effects of cilnidipine and amlodipine on ambulatory blood pressure. Hypertens Res. 2005;28(12):1003-1008.

20. Dangi NB, et al. Effect of Amlodipine, Cilnidipine and Diltiazem on lipid profiles of hypertensive rats fed with high fat diet: A com- parative study. Bulletin Facult Pharmacy Cairo Univ. 2016:1-7.

21. Masuda T, Ogura MN, Moriya T, Takahira N, Matsumoto T, Kutsuna T, Hara M, et al. Beneficial effects of L- and N-type calcium channel blocker on glucose and lipid metabolism and renal function in patients with hypertension and type II diabetes mellitus. Cardiovasc Ther. 2011;29(1):46-53.

22. Ahaneku JE, Sakata K, Uranol T, Takada Y, Takada A. Effects of cilnidipine on lipids, lipoproteins and fibrinolytic system in hypertensive patients. Drugs Exp Clin Res. 2000;26(4):119-123.

23. Sharp RP, Sirajuddin R, Sharief IM. Impact of carvedilol on the serum lipid profile. Ann Pharmacother. 2008;42(4):564-571.

24. Shravanthi Manthri, Dussa Veena, Ramesh babu Ambari, Goverdhan Puchchakayala. A Prospective Interventional Study on Clinical Effects of Cilnidipine in Hypertensive Patients. IJPRIF. 2015;8(10):70-76.

25. Skulas-Ray AC, West SG, Davidson MH, Kris-Etherton PM. Omega-3 fatty acid concentrates in the treatment of moderate hypertriglyceridemia. Expert Opin Pharmacother. 2008;9(7):1237-1248.

26. Jeppesen J, Hein HO, Suadicani P, Gyntelberg F. Triglyceride concentration and ischemic heart disease: an eightyear follow-up in the Copenhagen Male Study. Circulation. 1998;97(11):1029-1036.

27. Durrington PN. Triglycerides are more important in atherosclerosis than epidemiology has suggested. Atherosclerosis. 1998;141(Suppl 1):S57-62. 